\title{
El análisis de los policy networks: \\ ¿Una nueva perspectiva sobre la relación entre políticas públicas y Estado?
}

Jacint Jordana*

\section{El análisis de los policy networks y su desarrollo conceptual}

El estudio de la relación entre organizaciones de intereses y gobierno ha sufrido en los últimos años un conjunto de reformulaciones importante. Por una parte, el aumento de las investigaciones empíricas ha puesto en evidencia la incapacidad de los modelos tradicionales sobre la intermediación de intereses para interpretar la diversidad de formas de relación existentes'. Así, del énfasis tradicional en las características de las organizaciones de intereses, las nuevas investigaciones han dedicado mayor atención a las peculiaridades de las estructuras administrativas, como factor necesario para entender la naturaleza de las relaciones entre actores públicos y privados. Por otra parte, en los últimos años ha sido frecuente en muchos estudios sobre las políticas públicas, integrar de forma destacada el papel de las organizaciones de intereses, así como el de otros agentes externos a la Administración. Un resultado recurrente ha sido la constatación de que tales relaciones son muy distintas según los países y que, además, también difieren mucho según cada sector. La noción de policy networks -0 "redes de políticas públicas"- ha sido propuesta para afrontar las dificultades que experimentaban los análisis tradicionales, basados en la acción primordial de la burocracia, para explicar las políticas de distintos ámbitos sectoriales. En estas páginas se analizan algunos problemas que presentan las principales conceptualizaciones agru- padas bajo la noción de policy networks. Una vez esclarecidos, se repasa la relación entre la perspectiva analítica de los policy networks y algunos ámbitos destacados de la investigación reciente sobre los procesos político-administrativos de las sociedades industriales avanzadas, que replantean las interpretaciones teóricas tradicionales sobre el fenómeno estatal'. Esta revisión nos permite plantear si el análisis de los policy networks cuando se introduce el Estado como categoría teórica es clarificador, o bien es incompatible conceptualmente.

Desde la perspectiva del análisis de políticas públicas, la introducción del término policy network es una forma de reconocer que éstas emergen de la interacción entre actores públicos y privados, aceptando que la Administración ya no es el actor jerárquico y dominante en su elaboración e implementación, a pesar de que aún mantenga un destacado papel. Por otra parte, desde la perspectiva de las organizaciones de intereses, el término policy network ha servido para reconocer la existencia de dependencias mutuas entre lo privado y lo público, que afectan tanto a la dinámica interna de las organizaciones, como a sus mecanismos de actuación. Asimismo, desde ambas perspectivas, se coincide en entender que las decisiones políticas surgen en redes de actores, públicos y privados, que interactúan en ámbitos sectoriales o plurisectoriales; y en niveles regionales, nacionales o internacionales. Sin embargo, ¿qué son realmente los policy networks? ¿Se trata sólo de una metáfora descriptiva, utilizada con contenidos distintos por diferentes autores?, ¿se puede considerar como una aproximación global a un conjunto de modelos de intermediación de intereses entre el Estado y los actores sociales?, ¿o tal vez pueden identificarse unos contenidos más precisos bajo esta noción? Podemos 
avanzar ya que no se encontrará en estas páginas una respuesta definitiva a tales preguntas, porque, entre otros motivos, existen defensores de todos los puntos de vista. Por ello, no sorprende que entre los analistas de los policy networks su coincidencia más destacada consista en la concepción de los networks como estructuras, a medio camino entre las estructuras de mercado y las estructuras jerárquicas (Powell, 1990), donde las relaciones entre los participantes presentan un bajo nivel de formalización, intercambiando información y recursos.

Para situar el debate, es necesario empezar señalando que durante los años ochenta se produjeron numerosas interpretaciones que establecían distintas formas de relación entre Administración e intereses organizados en diversos ámbitos sectoriales. Poniendo su énfasis en uno $u$ otro factor, tales propuestas tomaron nombres diversos: policy sector, policy arena, policy community, policy game, policy domain, etc. (KENIS/SCHNEIDER, 1991), recuperando en algunos casos conceptualizaciones elaboradas en las décadas anteriores. Sin embargo, la noción más ampliamente aceptada actualmente para caracterizar tales relaciones es la de policy network, utilizada como un marco general en contextos sectoriales donde intervienen agentes públicos y privados, sin presuponer ningún modelo concreto, ni partir de una idea preconcebida sobre cómo deben ser las relaciones Administración-sociedad (MARIN/MAYNTZ, 1991; MARIN, 1990; JORDAN / SCHUBERT, 1992). La concepción subyacente es que tales relaciones pueden llegar a tomar formas muy distintas, que deben ser determinadas empíricamente. Como punto de partida se establece un conjunto de dimensiones a analizar, que se consideran claves para identificar la naturaleza del network (cuadro 1), para analizar posteriormente, con instrumentos de carácter cuantitativo -cuando se cree adecuado-, o bien con aproximaciones cualitativas, las características concretas de cada policy networks.

Una vez analizadas las diversas dimensiones que identifican un policy network, es frecuente que se intente relacionarlo con algún modelo sobre intermediación de intereses, o bien que se establezca alguna propuesta de carácter más teórico sobre la lógica de su funcionamiento. La combinación de este tipo de propuestas ha dado

\begin{tabular}{l} 
Principales dimensones y variables de los policy netuvorks \\
- Número de actóres \\
- Ambito de actuación \\
- Funciones básicas \\
- Estructura de las relaciones entre actores \\
- Estabilidad de las relaciones entre actores \\
- Grado de institucionalización de la red \\
- Reglas de conducta \\
- Distribución del poder \\
- Estrategias de los actores \\
\hline Fuente: Elaboracion propta
\end{tabular}

lugar, en los últimos años, a la formación de tipologías de policy networks, que suelen relacionar los diferentes rasgos existentes en las dimensiones consideradas con distintos modelos teóricos. Dado el estado tentativo en que se formulan estas interpretaciones, no es de extrañar que en las tipologías se encuentre en ocasiones una cierta superposición de términos, porque frecuentemente se intenta integrar en un mismo esquema conceptual, junto a nuevas propuestas analíticas, los modelos más tradicionales de intermediación de intereses. Sin embargo, el elemento que une a estas tipologías es, como señala Héritner, la descripción de núcleos de

"Actores públicos y privados (instituciones, organizaciones, grupos, individuos) y de sus interacciones. (...) Los miembros (...) dirigen, coordinan o controlan los recursos materiales o inmateriales en un ámbito de políticas públicas de interés común" (1993: 143-144).

Una de las dimensiones más utilizadas como criterio básico para la elaboración de tipologías es el número de actores que forman parte del network. Así, se destaca desde el network formado exclusivamente por agencias estatales, hasta el que integra un gran número de actores sociales, pasando por los networks con muy pocas organizaciones de intereses y los que también integran partidos políticos. Por ejemplo, la propuesta de van WAARDEN (1992a) relaciona el número y tipo de participantes en el network con el papel de la Administración, distinguiendo dos situaciones posibles: cuando existe delegación de autoridad pública en la implementación de las políticas, y cuando se produce exclusivamente el acceso -y la posibilidad de influencia- sobre la definición y formulación de las políticas. Además, también matiza en cada una de las dos situaciones si son las organizaciones de intereses o bien los departamentos estatales especializados los que tienen un mayor dominio sobre la orientación de las políticas que se llevan a cabo. A partir de los ejes mencionados, este autor construye un cuadro de doble entrada, que le permite situar diferentes modelos de intermediación de intereses en casillas distintas, definiendo cada modelo por la combinación específica de características que representa (cuadro 2).

Otra dimensión destacada para clasificar los policy networks es su ámbito de referencia. Por ejemplo, como muestra el cuadro 3 , WILKS y WrIGHT (1987) distinguen cuatro niveles posibles, según el grado de generalidad de los temas que abarca el network. Estos autores, así como MARSH y RHODEs (1992), defienden que el término Policy networks sólo debe referirse a ámbitos sectoriales, y que no puede ser aplicado directamente a niveles macro. Sin embargo, también necesitan incorporar otras dimensiones -como el estilo de interacción dominante- para poder especificar los distintos casos que pretenden integrar con su tipología. La propuesta de RHODES (MARSH / RHODES, 1992), bastante difundida en los últimos años', considera la existencia de un continuum de policy networks posibles, caracterizando detalladamente las variantes existentes en los dos extremos opuestos. Así, define las Policy Community como 


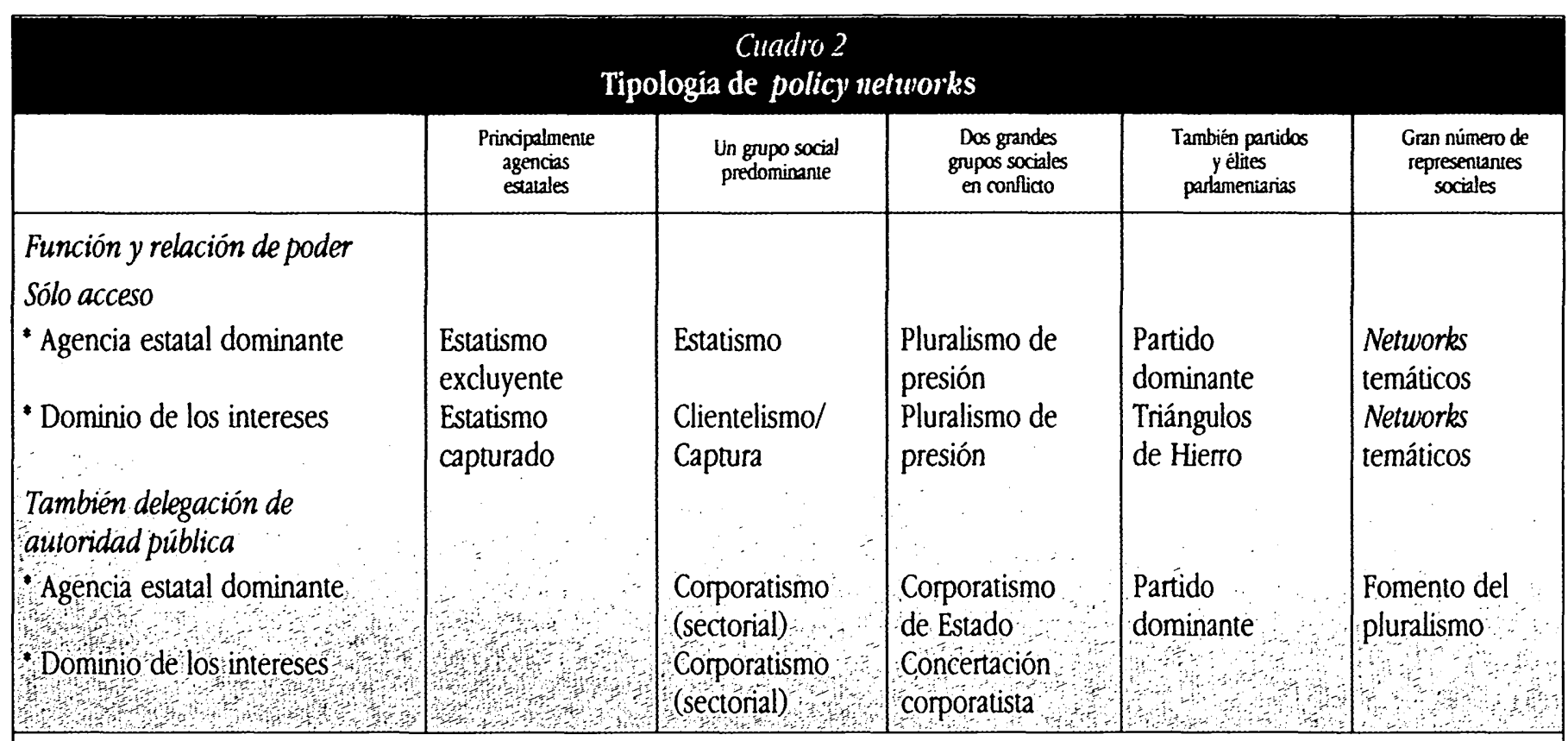

Fuente: Van WARDEEN (1992: 50).

los networks más estables y consistentes, mientras que sitúa los Issue networks como situaciones inestables, sujetas a continuos cambios (cuadro 4). Entre ambos extremos, señala otras configuraciones posibles, como los professional networks, los intergovernmental networks, o los producer networks.

En términos generales, los analistas de los policy networks coinciden en aceptar distintos aspectos como centrales para entender la dinámica interna de éstos. En primer lugar, se supone que los actores "negocian" constantemente su pertenencia al network, incluso en los casos más estables, con el objetivo de mejorar sus posiciones relativas e influir más intensamente en las decisiones sobre las políticas públicas de su interés. Un aspecto sobre el que se dedica mucha atención es sobre como se produce el intercambio de recursos y de información entre los actores situados dentro de los networks. Con planteamientos teóricos divergentes, se investigan los mecanismos que guían estos intercambios, señalándose que pueden consistir en reglas, rutinas informales, vínculos organizacionales, etc., que en cada caso limitan y estructuran los procesos y el estilo de interacción que se produce en el interior del network (SCharPF, 1989; Crawford / OStrom, 1992; KNOKE, 1990). Otro aspecto que también despierta gran atención es como estas reglas o rutinas contribuyen a definir los instrumentos específicos de gestión y dirección de políticas que son utilizados en el ámbito de referencia del network. En otras palabras, se trata de analizar cómo se generan las "ordenes" que fluyen en el interior de los networks y que acaban produciendo outputs específicos. Finalmente, los aspectos de desigualdad presentes en los networks concentran también una atención relevante. La capacidad de control sobre las políticas por parte de los diversos agentes es desigual, ya que depende del tipo y la cantidad de recursos y "habilidades" que cada uno de éstos dispone (SUBIRATS, 1989: 121). Por ello, se analiza en qué medida esta desigualdad (cuya valoración ya puede constituir en sí misma un elemento de discusión) influye en las formas de negociación y de compromiso que se producen, así como en el mayor o menor dominio en las decisiones del network por parte de las organizaciones de intereses, de la Administración o de otros agentes.

En este panorama de instituciones estatales y organizaciones de intereses adaptadas a las peculiaridades de cada policy network, para profundizar en su análisis, es necesario introducir más dimensiones que ayuden a entender su dinámica. En este sentido, los aspectos relacionados con la estructuración territorial de los networks configuran una de sus dimensiones mas significativas. Para el análisis de la dimensión territorial de los policy networks, el enfoque de las relaciones intergubernamentales ofrece un buen

\begin{tabular}{|c|c|c|}
\hline Denominacion & Nivel de politicas públicas & Ejemplos \\
\hline Área de politicas & $\begin{array}{l}\text { Grandes ámbitos secto- } \\
\text { riales }\end{array}$ & Sanidad, trabajo, industria \\
\hline Sector de políticas & Sectores delimitados & $\begin{array}{l}\text { Salud, industria quimica, } \\
\text { telecomunicaciones. }\end{array}$ \\
\hline Subsector de politicas & Subsectores especificos & $\begin{array}{l}\text { Prevención, regulación la- } \\
\text { boral, industria farmacéu- } \\
\text { tica. }\end{array}$ \\
\hline Tema de políticas & Problemas concretos & $\begin{array}{l}\text { Prevención sida, flexibili- } \\
\text { zación de contratos, pre- } \\
\text { cios farmaceuticos. }\end{array}$ \\
\hline \multicolumn{3}{|c|}{ Fuente: Adaptado de WILKS/WRIGHT (1987::300) } \\
\hline
\end{tabular}




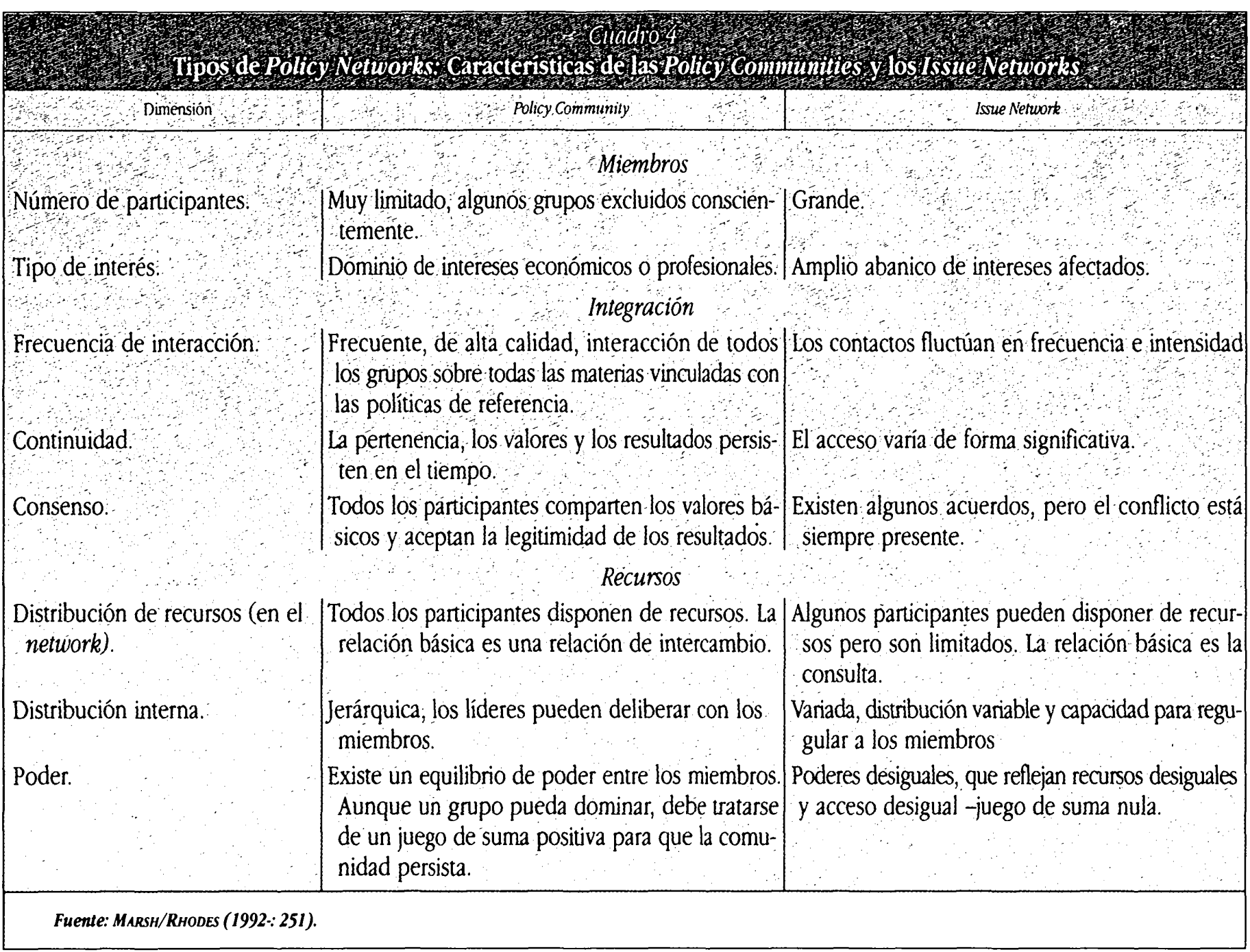

punto de partida, ya que afronta las relaciones entre distintos niveles de gobierno analizando los procesos de decisión e implementación de políticas (MORATA, 1991). Las dificultades de coordinación entre los diferentes niveles de la Administración (formas de decisión, mecanismos de control, objetivos divergentes, etc.) pueden ser más fáciles de comprender, cuando se refieren a un mismo ámbito sectorial, si se considera que cada nivel administrativo está integrado dentro de su propio segmento territorial del policy network correspondiente (DENTE, 1985). Así, el conjunto de segmentos territoriales de policy networks conforma a la vez un policy network de alcance más general (nacional o internacional), a pesar de que cada ámbito territorial mantenga posiblemente unas peculiaridades propias (MaYNTZ, 1990). En este sentido, considerar que cada nivel gubernamental tiene asociado su red de políticas es sólo un punto de partida, ya que hipotéticamente, pueden aparecer configuraciones bastante más complejas, con correspondencias cruzadas entre organizaciones de diversos niveles, dependiendo de la flexibilidad de negociación de las instituciones y organizaciones, de las reglas de decisión existentes y de los procesos de comunicación descentralizados que se producen (HANF / SCHARPF, 1978; BENZ, 1992).
El ejemplo de las investigaciones sobre políticas públicas y relaciones intergubernamentales en Alemania muestra algunas de las posibilidades de esta perspectiva de análisis. El federalismo cooperativo en Alemania ha sido criticado como un mecanismo de decisión demasiado inflexible, a causa de las ineficiencias que provocaban los procedimientos de decisión conjunta (SCHARPF, 1988), y también por la misma imposibilidad de transformar estas estructuras de decisión ineficientes. A pesar de ello, diversas investigaciones han mostrado que, manteniendo las mismas estructuras, se han producido importantes procesos de adaptación entre los agentes de los distintos niveles gubernamentales. Estas adaptaciones se han producido en los distintos ámbitos sectoriales -no de forma agregada-, y han facilitado la estabilidad de la estructura federal, evitando el colapso que podían producir los mecanismos de decisión establecidos (Benz, 1989). Para explicar estos procesos, se ha destacado la especial configuración de los policy networks sectoriales, fuertemente orientados hacia garantizar la homogeneización de las políticas (LeHmBRuCH, 1989: 228-231). Estas redes no presentaban una estructura centralizada y jerárquica, sino de intensa comunicación y coordinación entre los distintos núcleos 
regionales, donde predominaba generalmente el consenso en la formulación de objetivos. Así, frente al escaso centralismo de las instituciones estatales alemanas y las dificultades de los mecanismos de coordinación entre los Länder y el Bund, han predominado las formas de coordinación informal -entre Administración, organizaciones de intereses y partidos-, especialmente por lo que se refiere a los aspectos de la regulación económica del país (BENZ, 1989: 217-220).

\section{El análisis de los policy networks y los modelos de intermediación de intereses, ¿una convergencia de objetivos?}

La relativa convergencia en la utilización de la noción de policy network se ha producido mediante diversas vías, entre las que se cuenta la reformulación de las teorías tradicionales sobre los procesos de intermediación de intereses. Ello es debido a que las aproximaciones que defendían la preeminencia de un modelo específico para explicar las relaciones entre el Estado y las organizaciones de intereses -el pluralismo desde los años sesenta, el neocorporativismo durante los setenta y ochenta- han mostrado su agotamiento al acumularse importantes limitaciones para su aplicación como tipos ideales de los procesos sectoriales de intermediación de intereses, más allá de su adecuación a casos específicos.

En los inicios de la difusión del pluralismo, durante los años cincuenta, en la literatura politológica norteamericana se desarrollaron diversos modelos de policy-making que integraban les relaciones entre burocracia, políticos y organizaciones de intereses. Con las denominaciones de iron triangle, elastic nets, etc., se elaboraron modelos de interacción que analizaban la combinación de las relaciones formales e informales dentro de las redes -por ejemplo, el Congreso, la Administración y los lobbies-, así como la capacidad de exclusión e influencia de los actores que constituían estas redes (LowI, 1964, JoRDAN, 1981). No obstante, estos modelos no se desarrollaron con mayor profundidad a causa del predominio de una interpretación estandarizada sobre la acción de los grupos de interés en el paradigma pluralista de la ciencia políica norteamericana, que presuponía una estructura más descentralizada de las relaciones entre organizaciones de intereses y Administración, con la competencia abierta entre una multiplicidad de agentes ${ }^{10}$. No fue hasta fines de los años setenta, cuando en la ciencia política norteamericana volvieron a aparecer nuevas formulaciones que recordaban las aproximaciones anteriores a la estructura de adopción de decisiones dentro de ámbitos sectoria- les. Así, entre otras, aparecieron conceptualizaciones como policy community o issue network", que se presentaron como formas concretas de entender las especificidades que aparecían en las políticas públicas sectoriales. Evidentemente, según los temas y los ámbitos sectoriales, uno u otro modelo se ajustaba mejor para explicar la realidad, pero no existía la pretensión de desarrollar generalizaciones o tipologías, identificando las dimensiones más significativas.

Por otra parte, la difusión de los modelos neocorporatistas durante los años setenta (SCHMITTER/ LEHMBRUCH, 1979), en buena parte como reacción a la inadecuación de la aproximación pluralista a los sistemas políticos europeos, sirvió para popularizar una concepción alternativa de la articulación e intermediación de intereses en nuestras sociedades. Se postulaba la existencia de organizaciones de intereses centralizadas, con monopolio de representación reconocido por el Estado, la existencia de vínculos privilegiados -más o menos institucionalizados- con el gobierno y la Administración, y un intenso intercambio de recursos gestionado por las élites de las respectivas organizaciones (SCHMITTER, 1979). A pesar de la abundancia de variantes interpretativas que se propusieron (SANZ, 1994), las investigaciones empíricas desarrolladas durante los años ochenta a la luz de este enfoque mostraron que este modelo tampoco podía ser demasiado generalizado, ya que en los estudios de casos era necesario aplicar muchas matizaciones en las formas de analizar la estructura y los procesos de intermediación de intereses (LeHMBRuCH, 1985; Solé, 1987).

Las dificultades reseñadas fueron las que en buena parte condujeron -a lo largo de los años ochenta- hacia la difusión de la noción de policy network. Los problemas de validación empírica observados en los anteriores modelos eran debidos en parte a su carácter 'macro', que dificultaba una respuesta adecuada cuando se procedía a su evaluación en los niveles 'meso' y 'micro' (MARSH /RHODES, 1992). Ello no quiere decir que las perspectivas pluralista y corporatista hayan sido completamente abandonadas por sus defensores, y sustituidas por el análisis de los policy networks. Por el contrario, lo que han planteado ha sido la necesidad de su reformulación en el análisis sectorial, manteniendo algunos elementos centrales de sus respectivas perspectivas 'macro'. Una vez aceptada la idea que era necesario desarrollar otras conceptualizaciones, para poder disponer de mayor capacidad explicativa y aplicar a todos los ámbitos sectoriales, algunos de los continuadores de los enfoques 'macro' defendieron la utilización de la noción de network como metáfora. Como señala G. LEHMBRUCH, uno de los iniciadores del enfoque corporatista,

"La metáfora del network conlleva la idea de unas pautas sistémicas de relaciones interorganizacionales, las cuales deben su cohesión, así como su demarcación en relación con el entorno, a compartir significados vinculados con la interacción que se produce en el interior del network' (1991: 126). 
Para los autores que habían intervenido en las discusiones sobre el corporatismo, esta utilización del concepto de network como metáfora se consideraba más neutral y general, sin necesidad de referirse a una tipología de características concretas, y podia integrar -por ejemplo- el corporatismo como una forma concreta de network presente en muchos sectores. Entre otras formas consideradas también como policy networks, destacaban modelos clásicos, como el clientelismo o el estatismo, cada uno de ellos con sus propias características de estabilidad, amplitud y formas específicas de inclusión". Sin embargo, la aproximación al concepto de network como metáfora ha sido criticada por algunos investigadores debido a su ausencia de precisión, como señalan JORDAN y SCHUBERT:

"Sugerimos que la caracterización de los networks puede ser desarrollada usando diferentes dimensiones y cualidades más que a través de intentos de vincular éstos con algunos conceptos "paraguas" tales como el corporatismo o el pluralismo" (1992: 27).

En todo caso, se puede apuntar que el elemento de conflicto entre los defensores de la noción de policy network como metáfora y los que sostienen la necesidad de desarrollar tipologías bien definidas se encuentra en el peso relativo que se otorga a la perspectiva 'macro-social'. Mientras que el enlace con esta perspectiva es imprescindible para los primeros, para los segundos no es una cuestión excesivamente relevante. Esta situación puede ser debida al hecho de que, cuando se defienden caracterizaciones muy detalladas, se corre el riesgo de perder la perspectiva integradora sobre el conjunto, que los defensores de las aproximaciones 'macro' necesitan mantener de manera ineludible, ya que para sus interpretaciones teóricas tienen también en cuenta otras variables, distintas de las que se derivan de las relaciones entre la Administración y los intereses organizados. Una posible vía para solucionar esta oposición sería profundizar en el propio concepto de policy network, ensayando estrategias que permitieran disolver la incompatibilidad antes mencionada. Los intentos de precisar contenidos en el análisis de los policy networks no dejan de favorecer las posibilidades de integración entre los niveles 'macro' y 'meso', dando paso a que la 'metáfora' del network pueda ser sustituida por formulaciones más específicas. Así, aunque no necesariamente con el propósito de dar respuesta a estas cuestiones, los análisis recientes de los policy networks, partiendo de su caracterización como concepto útil para englobar diferentes modelos, han examinado detalladamente su funcionamiento. En este contexto, se han discutido tanto las condiciones de estabilidad de los networks, como los procesos de intercambio de recursos en su interior, pasando por las formas de adopción de decisiones o los mecanismos de entrada y salida del network, etc. (HÉrTTER, 1993; SCHARPF, 1993, KNOKE, 1990). Pero es precisamente cuando se profundiza respecto a estas cuestiones cuando se hace necesario introducir en la discusión las posibilidades que ofrecen perspectivas teóricas distintas, presentes en la ciencia política, que puedan introducir un ma- yor contenido explicativo en los modelos ya definidos, y desarrollar una lógica más sistemática sobre su dinámica.

A pesar de los desarrollos experimentados recientemente por el análisis de los policy networks, éste debe resolver aún muchos problemas pendientes para salir de la dimensión básicamente descriptiva y tipologizadora en que se encuentra actualmente situada. Para afrontar este reto, se pueden encontrar tres grandes corrientes que ofrecen posibilidades de profundizar en el estudio de la dinámica de los policy networks, existiendo ya diversos intentos en estas direcciones. Estas son: a) las teorías de origen económico -0 de la elección racional-, que partiendo de modelos basados en la teoría de juegos, definen el network como una estructura de interacción compleja, articulada a través de juegos conectados (TSEBELIS, 1990; SCHARPF, 1993b); b) la aproximación politológica desarrollada a través del nuevo institucionalismo, que combina el estudio de las instituciones políticas con las teorías de la organización; y c) la corriente sociológica, que aprovecha los desarrollos formales del análisis de redes sociales (SCOTT, 1991) aplicando este instrumental analítico a los actores políticos (LAUMANN / KNOKE, 1987, PAPPI, 1993). Las dimensiones de este artículo no permiten analizar de forma detallada los principios y las diversas teorías de las tres grandes corrientes mencionadas en relación al análisis de los policy networks. Por este motivo, nos centramos en analizar un problema concreto presente en el análisis empírico de los policy networks, que plantea retos importantes para el desarrollo teórico de esta perspectiva. Se trata de la vinculación e influencia recíproca entre las (nuevas) teorías del Estado y la interpretación de los policy networks. Aunque este problema no está relacionado prioritariamente con alguna de las grandes corrientes teóricas mencionadas anteriormente, si se pueden constatar unas afinidades especiales con ellas. Así, la reflexión sobre la integración teórica de los policy networks se produce especialmente dentro de la corriente de origen politológico, aunque sin duda deba combinarse con otras perspectivas para superar los problemas conceptuales existentes para unir el análisis de los niveles 'meso' y 'macro' en las relaciones entre la Administración y su entorno.

\section{La concepción del Estado y los policy networks}

Después de muchos años de escasa atención desde las corrientes dominantes de la ciencia política, desde los años ochenta la figura del Estado ha vuelto a estar en el centro de algunas de las principales polémicas politológicas (AıMOND, 1988), al mismo tiempo que se han multiplicado las investigaciones empíricas sobre aspectos específicos de los aparatos estatales (por ejemplo, KRASNER, 1984). Actualmente, orientaciones bastante distintas, que van desde el marxismo a la teoría de sistemas, pasando por la macrosociología y las revisiones de los enfoques clásicos de la cien- 
cia política, como puede ser el elitismo, compiten para dar una definición de su naturaleza y de sus contenidos (ALFORD / FrIEDLAND, 1985; Dunleavy / O'Leary, 1987). Por descontado, una discusión crítica de los principales enfoques actuales sobre las dimensiones y el papel del Estado es excesivamente compleja para poder ser presentada en estas páginas. El objeto que se plantea es mucho más modesto. Después de considerar brevemente cómo puede afectar la investigación reciente sobre los policy networks a la formulación de algunos enfoques teóricos sobre el Estado, se discuten -tomando como punto de partida el enfoque neoinstitucionalista- algunos ejes sobre los que reformular una noción valida de la figura del Estado en las sociedades altamente interconectadas de fines del siglo XX.

La perspectiva de los policy networks, con su énfasis en la diversidad sectorial de formas de organización y funcionamiento para la provisión de políticas públicas, ha alejado el análisis de los procesos de decisión pública de la descripción de las estructuras institucionales formales, y ha comportado en los últimos años, tal como destacan KenIS y SCHNEIDER,

"Un concepto descentralizado de organización social y de gobernabilidad: la sociedad ya no está controlada por una inteligencia central (p.e., el Estado); más bien los mecanismos de control están dispersos y la inteligencia se distribuye entre una multiplicidad de actores (o unidades de 'procesamiento')" (1991: 26).

Cabe recordar, no obstante, que hace ya algunos años Stein ROKKAN (1970) puso de relieve el papel de los networks y de las unidades de gobierno subnacional en los procesos de construcción de los Estados modernos, y destacó la necesidad de investigar las dimensiones sectoriales de agregación de intereses en conexión con el proceso de desarrollo administrativo de los Estados. En todo caso, cuando las sugerencias de RoKKan han sido constatadas -bastante tiempo después- la respuesta ha sido el cuestionamiento de la misma figura del Estado como objeto teórico útil para el estudio de las políticas públicas. Cada vez es más dificil defender una visión del Estado como una figura susceptible de tener intenciones, y con capacidad de articular -superando dificultadesdecisiones coherentes para el conjunto de sus diferentes organismos. La definición de los aparatos estatales como conjunto de instituciones y organizaciones con capacidad para definir y hacer cumplir decisiones sobre la sociedad en nombre de los intereses generales, a pesar de no presuponer una dirección unificada (JESSOP, 1990b: 45), se aleja demasiado de algunas situaciones contradictorias, como la ausencia de dirección o el dominio de los intereses organizados sobre la Administración, para poder tener una capacidad de aplicación general. Estos problemas son mostrados con claridad en los estudios sobre los policy networks, al analizar las interacciones que se producen entre estructuras político-administrativas públicas o semi-públicas y la diversidad de intereses sectoriales existente entre la población -expresados generalmente por medio de formas de representación organizada. No obstante, a pesar de las perspectivas de análisis que deja abiertas, el concepto de policy network difícilmente puede constituir un punto de partida para elaborar autónomamente una concepción propia sobre el Estado". Esta noción ayuda a clasificar las formas de relación entre la Administración y las asociaciones de intereses, y muestra la diversidad de actuaciones públicas, pero para ofrecer una explicación completa del proceso político y de sus resultados, el análisis de los policy networks se habría de vincular a una perspectiva 'macro' sobre la figura del Estado (MARSH / RHODES, 1992: 268), que aportara una lógica global sobre su funcionamiento.

A pesar de que las teorizaciones sobre el Estado son muy diversas, la relación entre el Estado y los intereses organizados ha sido caracterizada principalmente en la literatura politológica de los últimos decenios por medio de dos grandes orientaciones, que representaban dos principios opuestos: la competición y la cooperación. El primero era defendido por las aproximaciones pluralistas, mientras que el segundo tenia su modelo más representativo en la perspectiva corporatista. La tradición pluralista -precisamente por su escaso énfasis en el concepto de Estado- es la que más cercana se sitúa a la perspectiva que ofrece el análisis de los policy networks, al destacar la fragmentación de la autoridad estatal. Pero la investigación empírica sobre los modelos de intermediación de intereses mostró que las teorías pluralistas presentaban problemas importantes, tanto para integrar conceptualmente la diversidad de formas adoptadas por los networks" como por sus dificultades para articular el análisis de los diferentes sectores en una perspectiva conjunta o comparar un ámbito sectorial de políticas a través de diversos países (ATKInSON / COLEMAN, 1992: 163-167). Por otra parte, las aproximaciones corporatistas encontraron problemas similares -aunque en relación con casos inversos- a los del pluralismo: excesiva diversidad en el nivel 'meso' y escasa atención a la figura del Estado. Como decía G. LeHMBRuCH, reconociendo una debilidad de los estudios de carácter corporatista: "El Estado o la Administración no deben continuar siendo tratados simplemente como "cajas negras" (1987:1). En los últimos años, como resultado de tales dificultades, desde ambas perspectivas se dedicó una mayor atención al papel de la Administración. Sin embargo, tanto el corporatismo como el pluralismo no llegaron a desarrollar amplias teorizaciones sobre el Estado y la Administración, aparte de algunas aproximaciones y discusiones producidas en la segunda mitad de los años ochenta. Al mismo tiempo, las teorías tradicionales sobre el Estado, que podían recoger el reto ofrecido por el análisis de los policy networks, tampoco han sido utilizadas a fondo para integrar teóricamente las relaciones entre Estado y asociaciones de intereses.

Las teorías marxistas del Estado, que constituyen un amplio abanico de perspectivas (véase una revisión en JFsSOP, 1990), consideran -en general- que el Estado está dominado de forma indirecta por la clase capitalista. En este sentido, una de las tesis importantes en que a menudo se concreta esta hipótesis en las 
teorías marxistas del Estado -compartida también por algunos autores no marxistas- es el supuesto de la autonomía relativa del Estado en relación a los sectores dominantes de la sociedad. Las concreciones de esta tesis son muy variadas, y dan lugar a diversas escuelas y corrientes que divergen en su enfoque y en el análisis de los elementos clave de la relación entre el Estado y la sociedad (Held / Krieger, 1984; Dunleavy / O'Leary, 1987: 236-258). En los años setenta, el debate POULANZAS-MILBAAND enfrentó una visión determinista a una instrumentalista sobre la forma como la clase capitalista dominaba el Estado. En los años ochenta, otros enfoques tomaron el relevo, reconociendo que el Estado constituía un conjunto de instituciones, sin unidad propia, pero cuya "estructura y modus operandi estaban más abiertas a algunos tipos de estrategias que otras" (JESSOP, 1990: 260) en las confrontaciones entre fuerzas sociales para obtener poder estatal. Aunque existen diversas concreciones, puede ser útil plantear el núcleo central de esta tesis para confrontarla con los fenómenos expuestos anteriormente sobre la diversidad de los policy networks. Este núcleo se puede encontrar en el supuesto de dependencia de los recursos de Estado a una parte de la sociedad, tanto si este supuesto es defendido bajo unas hipotéticas necesidades funcionales, como derivado de la propia estructura organizacional del Estado (PrZEWORSKI / Wallerstein, 1986, 1988), en el sentido de asegurar los intereses a largo plazo de la clase capitalista.

A pesar de referirse a un nivel distinto de abstracción, la tesis de la autonomía relativa implicaría aceptar que la naturaleza del Estado se encuentra reflejada en las relaciones entre las instituciones estatales y las organizaciones de intereses. A partir de este supuesto, y considerando que las instituciones estatales están insertas en cada ámbito sectorial mediante sus correspondientes policy networks -con organizaciones y estructuras administrativas singulares-, en las cuales se reproducen diversos conflictos sociales, debería ser posible analizar cómo los intereses de clase se convierten en políticas públicas. Sin embargo, el problema reside en que las teorías marxistas han desarrollado escasas teorizaciones sobre los mecanismos estatales de selección estructural en los ámbitos sectoriales. La diversidad de formas de intervención pública existentes plantea bastantes interrogantes, ya que habría que defender -aunque sólo fuera en el caso de las coyunturas críticas-, que en las formas de representación e intervención propias de distintas caracterizaciones sectoriales se reproducen comportamientos encaminados a facilitar el funcionamiento a largo plazo del sistema económico capitalista. En todo caso, no se trata de resolver aquí este problema, sino de mostrar tan sólo que la perspectiva 'meso' que implica el análisis de los policy networks es también un reto importante para la evolución de las perspectivas teóricas marxistas".

En lo que se refiere a las teorías sobre el Estado influidas por el enfoque elitista, es necesario destacar que el análisis de los policy networks también aporta elementos para replantear el supuesto de que las élites políticas y sociales son las que dominan los pro- cesos de decisión en todos los ámbitos de las políticas públicas (DUNIEAVY / O'LEaRY, 1987). Las aproximaciones pluralistas sobre la dinámica de las asociaciones de intereses se encuentran bastante conectadas con el enfoque elitista, en el sentido de que aportan los elementos interpretativos sobre el proceso político que sustentan buena parte de las tesis elitistas. No obstante, la hipótesis de que el Estado no es otra cosa que un espacio de concentración (y confrontación) de élites políticas y sociales, debe ser reconsiderada, ya que aunque con frecuencia la toma de decisiones se produce en ámbitos dominados por élites políticas y sociales, aparecen dudas sobre el control continuo del proceso político por parte de las élites. Por un lado, se ha observado la existencia de ámbitos de políticas poco definidos, como en algunos temas de las políticas del medio ambiente, o también, networks que presentan una intensa fluctuación de actores y organizaciones. Por otra parte, la coherencia y el consenso entre las élites -un argumento de la teoría elitista para la estabilidad de la democracia liberal-también es puesta en duda por los analistas de los networks, al encontrar muy pocas conexiones entre las élites de los distintos ámbitos sectoriales (Heinz et al., 1990). Por estos motivos, la reformulación de una perspectiva sobre el Estado basada en el papel homogenizador de las élites en las redes de políticas plantea dificultades bastante importantes.

Como muestran las dificultades mencionadas, las perspectivas teóricas tradicionales sobre el Estado afrontan serios retos si pretenden integrar con detalle las aportaciones empíricas de los policy networks. Ello es debido en buena parte a que, tanto desde las perspectivas marxista como elitista-pluralista se considera al Estado como una condensación de fuerzas sociales (SmirH, 1993: 47), en un caso basado en el dominio de una clase social, en el otro suponiendo un atomismo de intereses representados por élites. En ambos casos, se produce una escasa atención a los intereses y recursos de los actores estatales, tanto en su capacidad de determinar políticas públicas como en su potencial de provocar reacciones específicas de grupos sociales frente al Estado. Al margen de los enfoques teóricos tradicionales, algunos investigadores sobre los policy networks consideran sin embargo que éstos ofrecen la oportunidad de redefinir aspectos importantes de la noción de Estado, apostando por una concepción de éste desde "abajo" hacia "arriba"; como destacan ATKINSON y Coleman (1992: 163) la cuestión es que: "Habiendo desagregado el Estado, los investigadores de esta tradición se enfrentan ahora al problema de volver a reagregarlo". Así, una estrategia de "reagregación" teórica debería partir presumiblemente de una aceptación de la diversidad de formas de acción presentes en los policy networks de diferentes sectores y países, para llegar a determinar con que pautas o procedimientos los networks sectoriales conforman los carácteres estatales dentro de nuestras sociedades contemporáneas. En este contexto, también sería necesario empezar a considerar a los networks -y no a sus elementos constituyentes-, como las unidades básica de análisis (DowDing, 1995: 137), donde sus propiedades fueran expli- 
cadas por una teoría propia. A continuación se discute esta sugerencia, incorporando algunos elementos de las aproximaciones neoinstitucionalistas, que tienen en cuenta la figura del Estado sin presuponer una estructuración predeterminada de éste.

\section{Hacia una redefinición de la relación entre políticas públicas y Estado}

Tal vez para construir un punto de partida diferente, sea útil recurrir al análisis de las instituciones políticas entendidas básicamente como conjuntos de reglas socialmente aceptadas y de concentraciones de recursos (MARCH / OLSEN, 1989). Se considera al Estado como una "colección" de instituciones y reglas, que integra una diversidad de actores públicos, cada uno con sus roles, restricciones y derechos específicos, cuya presencia puede ser fácilmente contemplada en los distintos policy networks. Descartando al Estado como actor unificado, para esta perspectiva no es necesaria una "función" o una "dirección" conjunta para concebir al Estado, sino que en cada uno de sus ámbitos de acción las instituciones políicas toman formas, comportamientos y objetivos diferentes, definidos según las características que presenten sus respectivos networks de políticas públicas. Como destaca OLSEN, ésta es la interpretación habitual de la perspectiva neoinstitucionalista:

"Las instituciones separan el mundo político en una multiplicidad de esferas más o menos independientes, basadas en distintos y posiblemente conflictivos principios, valores de apropiación y dinámicas" (OISEN, 1992: 253).

Partiendo de esta concepción, se podría destacar la ausencia de algún tipo de 'coordinación' conjunta, o una forma unitaria de acción, para continuar utilizando como concepto globalizador la noción de Estado: el Estado ya no es un actor unificado, sino una multiplicidad de actores, en todo caso conectados débilmente entre sí por numerosas reglas que no evitan el predominio de direcciones particulares y específicas por parte de cada uno de sus agentes. Desde esta perspectiva, la discusión sobre una autonomía global o relativa del Estado se desintegra, ya que en cada ámbito de políticas públicas los agentes estatales podrán actuar con dinámicas distintas. En unos casos impondrán sus preferencias frente a los actores sociales, mientras que en otros estarán dirigidos por intereses sociales".

Para dotar de carga teórica la noción de Estado, y no equipararla a sinónimo de organización pública, debería ser posible ensayar otras formas de abordar la lógica del impacto de lo público en nuestras sociedades. En este sentido, una posibilidad consiste en cambiar los ejes de observación -sin abandonar el análisis neoinstitucionalista- y pasar de considerar carácteres institucionales y comportamientos de actores a plantear dinámicas, relaciones y formas de "ordenar y representar la práctica social" (MrTcHEL, 1992: 1017), considerando los networks, y no los actores, como las unidades básicas de análisis. Esta perspectiva 'relacional', introducida por T. Mrtchel (1991) en su artículo "The Limits of the State: beyond statist approaches and their critics", niega que Estado y Sociedad sean unidades o espacios separables, argumentando que ambos son representaciones complejas de "lo social", donde se construye discursivamente el Estado como una estructura o como un agente intencional. Sin suscribir completamente los planteamientos de Miтcheu, sí cabe reconocer que algunas de sus argumentaciones pueden ser fructiferas para realizar una aproximación diferente a la figura del Estado, que permita relacionar este concepto global con los ámbitos sectoriales. Tomando como punto de partida su lógica de tipo "relacional", sería posible mantener la noción comprensiva del Estado, si se entendiera que su unidad -como abstracción- se deriva en buena pante de la propia percepción social que un amplio conjunto de estructuras públicas genera.

Al igual que no se identifica el conjunto de instituciones politicas existente en una sociedad con el Estado, al considerarse más amplio el primer concepto, no todas las formas, discursos y métodos con los que se construye lo público como argumento han de configurar una lógica para reconstruir la noción de Estado. En este sentido, estas páginas finales se dedican a examinar algunas interpretaciones sobre la relación entre instituciones e intereses en diversos ámbitos de la sociedad que analizan como se construye la percepción del Estado en distintos contextos sociales.

Un primer punto de vista que conecta la noción de Estado con los aspectos interpretativos de los actores colectivos lo podemos encontrar en Claus OfFE. Este autor concreta una posible línea interpretativa, derivada del enfoque marxista, sobre la relación entre el grado de auto-organización social en distintos ámbitos sectoriales y la capacidad de acción estatal. Intentando concretar su conceptualización, OfFe señala que

"El nivel de exigencia y la amplitud con que se llena de contenido el concepto de Estado (entendido como la suma de las tareas y del poder de intervención que le ha sido concedido), depende de la capacidad relativa de organización, movilización y conflicto, así como de la política de interpretación de los actores colectivos dentro de la civil society" (OFFE, 1990: 181).

Siguiendo con el punto de vista de C. OfFE, encontraríamos que en las situaciones que presentasen una menor articulación social, la representación del Estado correspondería a una escasa cohesión de sus actores y a una limitada capacidad de intervención pública en el ámbito correspondiente, mientras que, contrariamente, a mayor capacidad de autorregulación sectorial-social, el Estado se percibiría como una red cohesionada de actores públicos más fuertemente implicados en la construcción conjunta de instituciones de dirección en el respectivo ámbito sectorial-social. Offe destaca el 
caso de las relaciones laborales en Suecia como un buen ejemplo para mostrar un ámbito con un nivel extremo de organización y de institucionalización de los sectores sociales implicados, que se corresponde a una concepción social exigente de una elevada intervención estatal y de capacidad de regulación de la Administración. A pesar de ello, este mecanismo de creación de efectos estatales -en forma de poder de intervención pública- que sugiere OfFE, como relación lineal a la capacidad de organización social, no puede ser tomado como regla general. También existen muchos casos, aunque posiblemente en otras latitudes, en los que la autorregulación sectorial-social ha crecido sin impulsar la imagen de un fuerte desarrollo estatal en su ámbito correspondiente. Sin entrar a discutir su efectividad, el ejemplo de la compleja organización de las pensiones en los Estados Unidos muestra una situación inversa. Por este motivo, es necesario matizar la propuesta de OfFE, teniendo en cuenta el peso de las distintas tradiciones nacionales en la formación de los aparatos estatales".

Una perspectiva a partir de la que se podría rescatar otro carácter "relacional", apuntando a una línea interpretativa contraria a la de OfFe, es la que deriva de los estudios históricos comparativos sobre la figura del Estado, entre los cuales puede destacarse el libro Bringing the State Back In (Evans et al, 1985). Las investigaciones empíricas de esta línea del institucionalismo americano de los años ochenta han tenido cada vez más presente la capacidad de autonomía de las instituciones estatales. Han considerado al Estado como un agente activo, capaz de dar forma a la sociedad y de servir los intereses de los funcionarios -tanto o más que a los ciudadanos. Generalmente, esta capacidad de autonomía se ha entendido inserta dentro de cada policy network, y no como una capacidad de acción conjunta de las instituciones estatales, lo que ha limitado su capacidad de discusión teórica sobre la figura del Estado. Sin embargo, desde esta perspectiva se observa que es la capacidad de autonomía la que permite dirigir, regular o incentivar en diferentes ámbitos sectoriales formas organizativas y movilizaciones de recursos (SKOCPOL, 1985). Así, por ejemplo, se entiende que la forma como se configuró la estructura de los seguros y las pensiones en los Estados Unidos es la consecuencia de las concepciones impuestas por las instituciones estatales en este ámbito. Independientemente de las formas organizativas que presentan los participantes en el policy network, y de las propias pautas de funcionamiento de cada ámbito o sector, se considera que los aparatos administrativos tienen una cierta capacidad, de dimensión variable en cada caso, para alterar las reglas del juego de sus respectivos networks". A partir de estas ideas sobre los agentes estatales, el carácter de representación social inscrito en la visión "relacional" surgiria precisamente de las percepciones y expectativas que generan un conjunto de exigencias sociales sobre lo publico, en networks de escasa diferenciación entre gobierno y sociedad. Así, estas exigencias vendrían limitadas por los márgenes que establece la relación de adaptación de los aparatos administrativos a las condiciones y el nivel de organización social.
Estas dos interpretaciones sobre la creación de efectos y representaciones del fenómeno estatal a partir de casos sectoriales se inscriben dentro de lo que podría ser entendido como un amplio panorama de propuestas teóricas sobre los mecanismos y métodos con los que se construye continuamente la representación sobre la que se asienta nuestra idea de Estado: la relación -cada vez más compleja- entre conjuntos de instituciones políticas y ámbitos sociales con distintos grados de especificidad. Por un lado, desde recomposiciones de la tradición marxista, como la propuesta por C. Offe, se afirma que un nivel elevado de movilización y de organización de la sociedad civil impulsa un desarrollo creciente de las instituciones publicas. Por otra parte, desde las nuevas interpretaciones asentadas en la tradición pluralista, se argumenta que las Administraciones públicas tienen una capacidad importante para modificar las estructuras de relación con los agentes sociales, y de afectar incluso la misma configuración de éstos, y que -por tanto- no reaccionan siempre miméticamente a las presiones sociales y a los grupos organizados. No obstante, tal como se ha mostrado, adoptando una perspectiva "relacional" se pueden llegar a redefinir elementos de ambas perspectivas que cumplen una función análoga. En ambos casos, las percepciones sociales que conforman la representación del Estado no se producen de forma coordinada por medio de las estructuras estatales o de los diversos ámbitos sociales, sino que pueden ser comprendidas como iniciativas, presiones o respuestas -en cada caso de reacción o de anticipación-a las condiciones de policy networks específicos de cada ámbito sectorial de producción de políticas.

Para desarrollar el contenido de la perspectiva "relacional" sobre el Estado, aprovechando las distintas aportaciones del nuevo institucionalismo (incluyendo las que toman una mayor influencia marxista), podría ser de interés profundizar sobre las relaciones de causalidad entre sociedad civil e instituciones políticas, como forma de hacer aflorar los mecanismos y métodos de creación de distinciones entre el mundo del Estado y el mundo social -como propiedades de los networks. Sin embargo, la tarea desborda los propósitos de este trabajo, por lo que sólo se apuntan algunas propuestas teóricas que analizan formas de generar percepciones sociales. Por un lado, el análisis de los elementos simbólicos y culturales que actúan como reflejos sociales y son fácilmente utilizados como movilizadores o como cohesionadores; $y$, por otro lado, los estudios sobre la lógica de la acción colectiva y sus mecanismos de activación e incentivación.

La consideración de los elementos simbólicos en la conceptualizaciones sobre el Estado ha devenido un tema recurrente dentro de la historia de la teoría política." Desde el nuevo institucionalismo se ha recuperado esta dimensión, a pesar de que no se han producido desarrollos teóricos importantes. En este sentido, la interpretación que realizan FRIEDLAND y ALFORD es una buena muestra de esta nueva sensibilidad: "las instituciones son sistemas simbólicos con referentes no observables, absolutos y transnacionales y con relaciones sociales que concretan esos referentes. A 
través de estas relaciones sociales concretas, los individuos y las organizaciones se aplican al logro de sus fines, pero también confieren significado a la vida y reproducen esos sistemas simbólicos ${ }^{n}$ (1993: 184). Así, parafraseando un conocido artículo de C. GEERTZ (1973), "La ideología como sistema cultural", se podría entender que la percepción unificada del Estado es posible gracias a que éste constituye un sistema cultural, en el cual su memoria social activa puntos de referencia sobre el orden social, en contextos diferenciados y altamente cambiantes de formas institucionales (GRANDE, 1993), que entre otras cosas, permiten también generar elementos simbólicos que faciliten la aparición de mecanismos de articulación de identidades diferenciadas .

El desarrollo teórico sobre la lógica de la acción colectiva (OuVER, 1993) puede constituir una fuente importante de nuevas aportaciones para el estudio de los policy networks, permitiendo elaborar modelos más precisos sobre el comportamiento de las organizaciones de intereses y las lógicas de actuación en ámbitos sectoriales. El análisis de los incentivos organizacionales, la combinación de diversos intereses para organizar y mantener formas de acción colectiva, los mecanismos que sustentan el liderazgo, etc., son algunos de los aspectos analizados, que permiten comprender mejor cuáles son las posibilidades organizativas para la articulación de intereses sociales. Así por ejemplo, la concepción atomista de las organizaciones de intereses que representaba el modelo pluralista o la concepción monopolista del modelo corporatista, pueden ser entendidas como dos casos entre las muchas formas posibles en que se puede concretar la acción colectiva. En cierto modo, la acción colectiva se construye a partir de percepciones sobre características específicas de los bienes públicos, que son las que finalmente facilitan que se desencadenen acciones de participación individual, provisiones de recursos, etc. Por tanto, la pugna por la construcción de percepciones sobre lo público es una tarea constante para cualquier organización de intereses -en beligerancia con otras organizaciones, según el tipo de network en que esté inserta-, tanto para conseguir sus fines frente a instituciones encargadas de asignar recursos o fijar reglas, como en lo que se refiere a dinamizar la acción colectiva que sustenta a la organización.
A pesar de los intentos realizados por algunos autores para relacionar el análisis de los policy networks con la figura del Estado, explorando incluso algunas posibles líneas de trabajo, o de posibles "reconceptualizaciones", como la apuntada en estas páginas, la ausencia de un mayor nivel de teorización propia sobre los networks se hace notar, limitando bastante las posibilidades de cualquier desarrollo analítico. Cabe recordar que la misma definición del concepto está sometida a fuertes controversias, y que su utilización en uno u otro sentido -más allá de la aplicación metafórica- parece demasiado general, basado principalmente en caracterizaciones, y demuestra una escasa precisión de los contenidos que proclama. Sin embargo, también es necesario recordar que el estudio -básicamente descriptivo- de los policy networks sectoriales supone un importante reto para algunas de las teorías tradicionales sobre el Estado, al confrontarse sus aproximaciones de carácter 'macro' con unas investigaciones de ámbito 'meso' y 'micro' que no responden a los planteamientos establecidos. Por ello, las investigaciones empíricas sectoriales enmarcadas por elaboradas tipologías no dejan de constituir un foco que reclama la atención de los analistas de procesos macropolíticos.

Finalmente, sólo resta señalar que junto a las reflexiones teóricas sobre la naturaleza y los problemas de las conceptualizaciones sobre el Estado, para responder a las confrontaciones teóricas existentes, son siempre necesarias nuevas investigaciones empíricas, que usualmente toman cuerpo en ámbitos sectoriales. A la vez, es deseable que estas investigaciones sean sensibles a determinadas hipótesis teóricas sobre la naturaleza del Estado y las transformaciones de los procesos político-administrativos contemporáneos. En la medida que se desarrollen programas de investigación dentro de aproximaciones teóricas bien establecidas, posiblemente las conexiones entre las perspectivas 'macro' y 'micro' podrán definirse con mayor detalle. Así, si progresa el análisis teórico de los policy networks -posiblemente haciendo uso de teorías más básicas (redes sociales, teoría de juegos, etc.)-su posible contribución a la comprensión de los grandes procesos e instituciones políticas (incluyendo la figura del Estado) pasará de ser sólo una señal de atención empírica a constituir un campo de elaboración teórica prometedor.
- Profesor Titular de Ciencia Política. Universidad Pompeu Fabra. Barcelona.
I Siguiendo la literatura especializada, el término "intermediación" se emplea para
describir el proceso mediante el cual se expresan y se reconcilian los intereses de
organizaciones o grupos de intereses y gobierno.
2 Dos coincidencias pueden haber favorecido este proceso de "reconocimiento":
la primera, la expansión durante los años setenta de las enseñanzas articuladas
en tomo al estudio de les políticas públicas, tanto en los Estados Unidos como en
Europa, que produjeron el aumento de especialistas e investigadores en diversos
ámbitos sectoriales (JanN, 1986). La segunda, los propios procesos de desjerar-
quización del Estado (SCHARPF, 1991) pueden haber hecho más evidente durante
los años ochenta -a pesar de la habitual lentitud de las transformaciones estata-
les- la diversidad de formas de regulación y dirección de las políticas públicas. 
7 Véanse por ejemplo las revisiones de DowDing (1995) o PETERSOn (1995).

${ }^{8}$ En el primer extremo, se presupone la existencia de una comunidad bastante cerrada, con unas percepciones compartidas, interdependencia vertical y con articulación horizontal limitada; inversamente, en el segundo extremo se considera que hay escaso consenso intemo, la participación es grande pero inestable, que la interdependencia vertical es limitada y que el espacio de discusión política se constituía ad hoc. En los casos intermedios, se considera que se va reduciendo la interdependencia vertical y aumenta la articulación horizontal, al mismo tiempo se reduce la estabilidad de la participación, conforme se aproxima al tipo de issue network (RHODES / MARSH, 1992: 14).

9 Véase JORDAN (1990) para una revisión histórica de estas concepciones.

10 Véanse, por ejemplo, los trabajos de R. DAHL $(1971,1976)$. Ya en los años setenta, se produjeron reformulaciones de este enfoque -conocidas bajo el nombre de 'neopluralismo'-, que reconocian las deformaciones del modelo pluralista, como por ejemplo, la siruación privilegiada de las organizaciones empresariales frente otros grupos (LINDBLom, 1977; DunleaVy /O' LEARY, 1987).

"Definido por HeClo (1978), y elaborado con mayor detalle posteriormente por RHODES (MARSH / RHODES, 1992).

12 La tipologia de van WAARDEN (1992) se inscribe precisamente dentro de esta línea.

13 Como señala Dowding (1995: 140-141), desde la perspectiva de los networks sólo se han realizado sistemas de clasificación, pero no explicaciones sobre como se comportan actores diferentes (instituciones, grupos, ...) $-\mathrm{o}$ los propios networks- bajo diferentes condiciones institucionales.

14 Por un lado, se ha observado que los Estados no muestran las mismas formas de intervención en todos los ámbitos de políticas sectoriales (ATKINSON / COLEMAN, 1989); por otra parte, se ha constatado frecuentmente la coexistencia de situaciones de cooperación y conflicto en un mismo entorno de formación y aplicación de políticas (SCHaRpF, 1993b).

is Uno de los pocos ensayos de desarrollar un contexto macroteórico para los networks desde estas perspectiva lo constituye el trabajo de BENSON (1982), que considera que "la estructura y las contradicciones de cada sector de políticas públicas están vincula-das a la lógica de desarrollo del Estado capitalista", y que por tanto, las dependencias interorganizacionales de recursos constituyen la estructura de la dominación de clase (1982: 176).

16 NoRDUnger (1981) destaca tres tipos de autonomía estatal: la primera, cuando las preferencias entre Estado y sociedad divergen y los actores estatales actúan según sus propias preferencias; la segunda, cuando existiendo divergencias, los agentes estatales consiguen alterar las preferencias sociales para su conveniencia; y la tercera, cuando ya existe coincidencia entre preferencias estatales y sociales, y el Estado sigue sus propias preferencias, aunque pueda dar la impresión de que se deja convencer.

17 Desde esta perspectiva, la existencia de estilos de gobierno y de las tradiciones políicas nacionales, que afectan y condicionan el conjunto de los policy networks sectoriales de cada país (VAN WAARDEN, 1992b), podrían ser entendidos como consecuencia de las diversas cristalizaciones político-sociales existentes en cada pais.

18 Cabe destacar, sin embargo, que la capacidad de regulación de los policy networks es limitada -y desigual. Asi lo destacan per ejemplo LINDBERG y CAMPBELL (1991: 360-361), en su estudio sobre las formas de gobierno de la economía americana, señalando que "El Estado constituye la economia instrumentalmente como un conjunto de actores, y estructuralmente proveyendo 'arenas' políticas y configuraciones organizacionales a través de las cuales se elabora y aplica la política económica, al mismo tiempo que se definen espacios en los que se produce la actividad económica".

19 Desde tradiciones muy distintas, véanse, por ejemplo, los trabajos de GeERTz (1980) o bien de Garcia Pelayo (1968).

20 Un trabajo clásico de los años cincuenta (LoNG, 1958) ya apuntaba estas ideas al destacar la existencia en una misma comunidad de relaciones "ecológicas" entre distintos subsistemas (que también podriamos llamar juegos, o networks): "semi-autónomos pero regularmente recíprocos, internamente racionales pero sin compantir necesariamente una racionalidad común, hasta cierto punto competitivos pero manteniendo algunas interdependencias mutuas" (1958: 251).

\section{Bibliografia}

Alford, Robert R. / Friedland, Roger (1985): Powers of Theory, Cambridge University Press, Cambridge.

ALmoND, Gabriel A. (1988): "The Return to the State", American Political Science Review, 82.

AtKunson, Michael M. / Coleman, William D. (1992): "Policy Networks, Policy Communities and the Problems of Governance", Governance, 5.

ATKINSON, Michael M. / Colfmav, William D. (1989): "Strong States and Weak States: Sectorial Policy Networks in Advanced Capitalist Economies", British Journal of Political Science, 19.

Benson, J.A. (1982): "A Framework for Policy Analysis", en D. Rogers / D. Whitten et al. (Eds.), Interorganizational coordination, lowa State University Press, Ames.

BeNz, Arthur (1992): "Verhandlungssysteme und Mehrebenen-Verflechtung in kooperativen Staat", Mimeo, Constanza.

BENz, Arthur (1989): "Intergovernmental Relations in the 1980s", Publius. The Journal of Federalism, 19.

GrawFord, Sue / OSTROM, Elinor (1992): "Studying rules and norms: Linking individuals and context", ECPR, Mimeo, Limerick.

DAHL, Rober (1976): Análisis politico modermo, Fontanella, Barcelona.

DAHL, Robert (1971): Poliarchy: Participation and Oposition, Yale University Press, New Haven.

DENTR, Bruno (1985): Governare La Frammentazione, Mulino, Bolonia.

DowDing, Keith (1995): "Model or Methaphor? A Critical Review of the Policy Network Approach", Political Studies, 48.

DuniEAVY, Patrick / O'LEARY, Brendan (1987): Theories of the State, MacMillan, Houndmills.

EvansS, P. R. / RUESCHEMEYER, D. / SKOCPOL, T. (1985): Bringing the State Back In, Cambridge University Press, Cambridge.
FRIEDLAND, Roger / AIFORD, Robert R. (1993): "La sociedad regresa al primer plano: símbolos, prácticas y contradicciones institucionales", Zona Abierta, 63/64 (original en inglés: "Bringing Society Back In: Symbols, Practices and Institucional Contradictions", a W. Powell y P. DiMaggio (Eds.), The New Institutionalism in Organizational Analysis, Chicago University Press, Chicago, 1991).

Garcia Pelayo, Manuel (1968): "Del mito y de la razón en el pensamiento politico", Revista de Occidente, Madrid.

GEeRTZ, Cliford (1973): "La ideología como sistema cultural", en La interpretación de las culiuras, Gedisa, México, 1987.

GEERTZ, Cliford (1980): Negara: the Theather State in Nineteenth Century Bali, Princeton University Press, Princeton.

Grande, Edgar (1993): "Die neue Architektur des Staates", en R. Czada y M.G. Schmidt (Eds.), Verbandlungsdemokratie, Interessenvermittlung, Regierbarkeit, Westdeutscher Verlag, Opladen.

HANF, Kenneth / SCHARPF, Fritz W. (Eds.), (1978): Interorganizational Policy Making, Sage, Londres.

HECLO, Hugh (1978): "Issue Networks and the Executive Establishment", en A. King (Ed.): The American Political System, American Enterprise Institute, Washington.

HeClo, Hugh / WiLdavsky, Aaron (1974): The Private Govermment of Public Money, MacMillan, Londres.

HEInZ, John P. et al. (1990): "Inner Circles or Hollow Core? Elite Networks in National Policy Systems", Jourmal of Politics, 52.

HELD, David / KRIECER, Joel (1984): "Theories of the States: Some Competing Claims", en S. Bornstein et al. (Eds.), The State in the Capitalist Europe, Allen \& Unwin, Londres.

HermtTer, Adrienne (1993): "Policy Network Analysis: A Tool for Comparative Political Research", a H. KEMAN (Ed.), Comparative Politics: new directions in theory and metbod, VU University Press, Amsterdam. 
JANs, Werner (1986): "Politikwissenschaftiche Verwalrungforschung", en K. von Beyme (Ed.), Politikwissenscbaft in der BRD, PVS-Sonderheft 17, Westdeutscher Verlag, Opladen.

Jessop, Bob (1990a): State Theory, Cambridge University Press, Cambridge. JEsSoP, Bob (1990b): "Putuing States in Their Place: State Systems and State Theory", en A. Leftwith (ed.), New Developments in Political Science, Edwar Elgar, Aldershot.

JORDAN, Grant / SchUBERT, Klaus (1992): "A preliminary ordering of policy network labels", European Joumal of Political Research, 21.

JORDAv, Grant (1990): "Sub-Govemments, Policy Communities and Nerworks. Refilling the Old Bottles?", Joumal of Theoretical Politics, 2.

JorDav, Grant (1981): "Iron Triangles, Woolly Corporatism and Elastic Nets: Images of Policy Process", Joumal of Public Policy, 1.

Kenis, Patrick / Schneider, Volker (1991): "Policy Networks and Policy Analysis: Scrutinizing a New Analytical Toolbox", a B. Marin i R. Mayntz (Eds.), Policy Networks.

KNOKE, David (1990): Political Networks. Thre Structural perspective, Cambridge University Press, Cambridge.

Krasner, Stephen (1984): "Approaches to the State: Alternative Conceptions and Historical Dynamics", Comparative Politics, 16.

LAUMAvN, Edward O./KNoKE, David (1987): The Organizational State, University of Wisconsin Press, Madison.

LEHMBRUCH, Gerhard (1991): "The Organization of Society, Administrative Strategies and Policy Networks", en R. Czada y A. Windhoff-Héritier (Eds.), Political Choice, Campus, Frankfurt.

LeHMBRUCH, Gerhard (1989): "Institutional Linkages and Policy Networks in the Federal System of West Germany", Publius. The Journal of Federalism, 19.

LEHMBRUCH, Gerhard (1987): "Comparative Political Economy of Neo-Corporatism: Interorganizational and Institutional Logics", ECPR, Amsterdam.

LeHMBRUCH, Gerhard (1985): "Concertation and the Structure of Corporatist Networks", en J. Goldthorpe (Ed.), Order and Conflict in Contemporary Capitalism, Clarendon, Oxfor.

LINDBFRG Leon N. / CAMPBELL, John L. (1991): "The State and the Organization of Economic Activity", en J. Campbell, J. Hollingsworth y L. Lindberg (Eds.), Governance of the American Economy, Cambridge University Press, Cambridge.

LindBlom, Charles (1977): Politics and Markets, Basic Books, New York.

LONG, N.E. (1958): "The local community as an ecology of games", American Journal of Sociology, 63.

Low, Theodore (1964): "American Business, Public Policy, Case Srudies and Political Theory", World Politics, 16.

MARIN, Bernd (Ed.), (1990): Governance and Generalized Exchange: Self Organizing Policy Networks in Action, Campus, Frankfurt.

Marin, Bernd / MaynTz, Renate (Eds.), (1991): Policy Networks. Empirical Evidence andTheoretical Considerations, Campus, Frankfurt.

MarCh, James G. / OLSEN, Johan P. (1989): Rediscovering Institutions, Free Press, New York

MARSH, David / RhODES, R.A.W. (1992): "Policy Communities and Issue Nerworks. Beyond Typology", en D. Marsh y R.A.W. Rhodes (Eds.), Policy Networks in British Government, Clatendon Press, Oxford.

MAYNTZ, Renate (1990): "Organisierte Interessenvertretung und Föderalismus: Zur Verbändestruktur in der Bundesrepublik Deutschland", en Th. Ellwein et al., Jabrbuch zur Staats- und Verwaltungswissenschaft, 4, Nomos Verlag, BadenBaden.

MenY, Yves / Thofnig, Jean (1991): "Políticas públicas y teoría del Estado", Documentación Administrativa, 224-225.

MitCHFLL, Thomas (1991): "The Limits of the State: beyond statist approaches and their critics", American Political Science Review, 85.

Mrtchell, Thomas, et al. (1992): "Going Beyond the State?", American Political Science Review, 86.

Morata, Francesc (1991). "Políticas públicas y relaciones intergubernamentales", Documentacion Administrativa, 224-225.

NORDINGER, E. (1981): On the Autonomy of Democratic State, Harvard University Press, Cambridge.

OFFE, Claus (1990): Staatliches Handeln und Strukturen der kollektiven Willensbildung - Aspekte einer sozialwissenschaftlichen Staatstheorie", en T. Ellwein y J.J. Hesse (Eds.), Staatswissenschaften: Vergessene Disziplin oder neue Herausforderung?, Nomos, Baden-Baden.
OrFe, Claus (1987): "Die Staatstheorie auf der Suche nach ihrem Gegenstand. Beobachtungen zur aktuellen Diskussion", en T. Elwein et al. (Eds.), Jabrbucb zur Staats-und Verwaltungsurssenscbafi, 1, Nomos, Baden-Baden.

Ouver, Pam (1993): "Formal models of Collective Action", Annual Review of Sociology, 20.

OLSEN, Johan P. (1992): "Analyzing Institutional Dynamics", Staalswissenschaften und Siaatspraxis, 3.

PAPPI, Franz U. (1993): "Policy-Netze: Erscheinungsform moderner Politiksteuerung oder methodischer Ansatz" Neuorientienung, PVS-Sonderhefi, 24.

PETERSON, John (1995): "Policy Networks and European Policy making: A Reply to Kassim", West European Politics, 18.

Poweu, W.W. (1990): "Neither Market nor Hierarchy: Nerwork Forms of Organization", Research in Organizational Behavior, 12.

PrzewORSKI, Adam / WALLERSTEIN, Michael (1986): "Popular sovereignty, State autonomy, and private property", Arcbives Europeenes de Sociologie, 27.

PrZEworsKI, Adam / WALLRSTETn, Michael (1988): "Structural Dependence of the State on Capital", American Political Science Review, 82.

RHoDes, R.A. (1990): "Policy Networks. A British Perspective", Journal of Theoretical Politics, 2.

RoKkan, Stein (1970): Citizens, Elections, Parties, Universitatsforlaget, Oslo.

SAvz, Luis (1994): "El corporatismo en las sociedades industriales avanzadas. Veinte aǹos de debates sobre intermediación de intereses y políticas públicas", Zona Abierta, 67/68.

ScoTt, John (1991): Social Network Analysis, Sage, Londres.

SCHARPF, Fritz W. (1993): "Versuch über Demokratie in verhandelnden Staat", en R. Czada y M.G. Schmidt (Eds.), Verhandlungsdemokratie, Interessenvermittlung, Regierbarkeit, Westdeutscher Verlag, Opladen.

Scharpf, Fritz W. (1993b): "Coordination in Hierarchies and Networks", en F. Scharpf (Ed.), Games in Hierarchies and Networks. Analytical and Empirical Approaches to the Study of Gevernance Institutions, Campus, Frankfurt.

SCHARPF, Fritz W. (1991): "Die Handlungsfähigkeit des Staates am Ende des zwanzigsten Jahrhunderts", Politische Vienteljabresschrift, 32.

SCHARPF, Fritz W. (1989): "Decision rules, decision styles and policy choices", Journal of Theoretical Politics, 1 .

SCharpF, Fritz W. (1988): "The Joint-decision Trap: Lessons from German Federalism and European Integration", Public Administration, 66.

SCHmitTer, Philiphe C. (1974): "Still the Century of Corporatism?", Review of Politics, 36.

SCHmitter, Philiphe C. / LehmBruch, Gerhard (Eds.), (1979): Trends Toward Corporatist Intermediation, Sage, Londres.

SkocPol, Theda (1985): "Bringing the State Back In: Strategies of Analysis in Current Research", en P.R. Evans, D. Rueschemeyer y T. Skocpol, (Eds.), Bringing the State Back In, Cambridge University Press, Cambridge.

Smith, Martin J. (1993): Pressure, Power E Policy, Harverster \& Wheatsheaf, Londres.

Solf, Carlota (Ed.), (1987): Corporatismo y diferenciación regional, MTSS, Madrid.

SURIRATS, Joan (1989): Análisis de políticas y eficacia de la Administración, MAP, Madrid.

TSEBFLus, George (1990): Nested Games. Rational Choice in Comparative Politics, University of California Press, Berkeley.

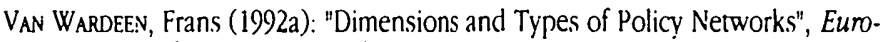
pean Journal of Political Research, 21.

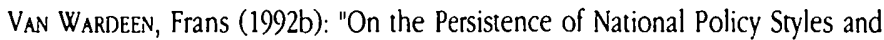
Policy Networks", Conferencia sobre "Policy Networks", Mimeo, Freudenberg. WILKS, Steven / WRGHT, Maurice (Eds.), (1987): Comparative Gevernment-Industry Relations, Clarendon, Oxford. 


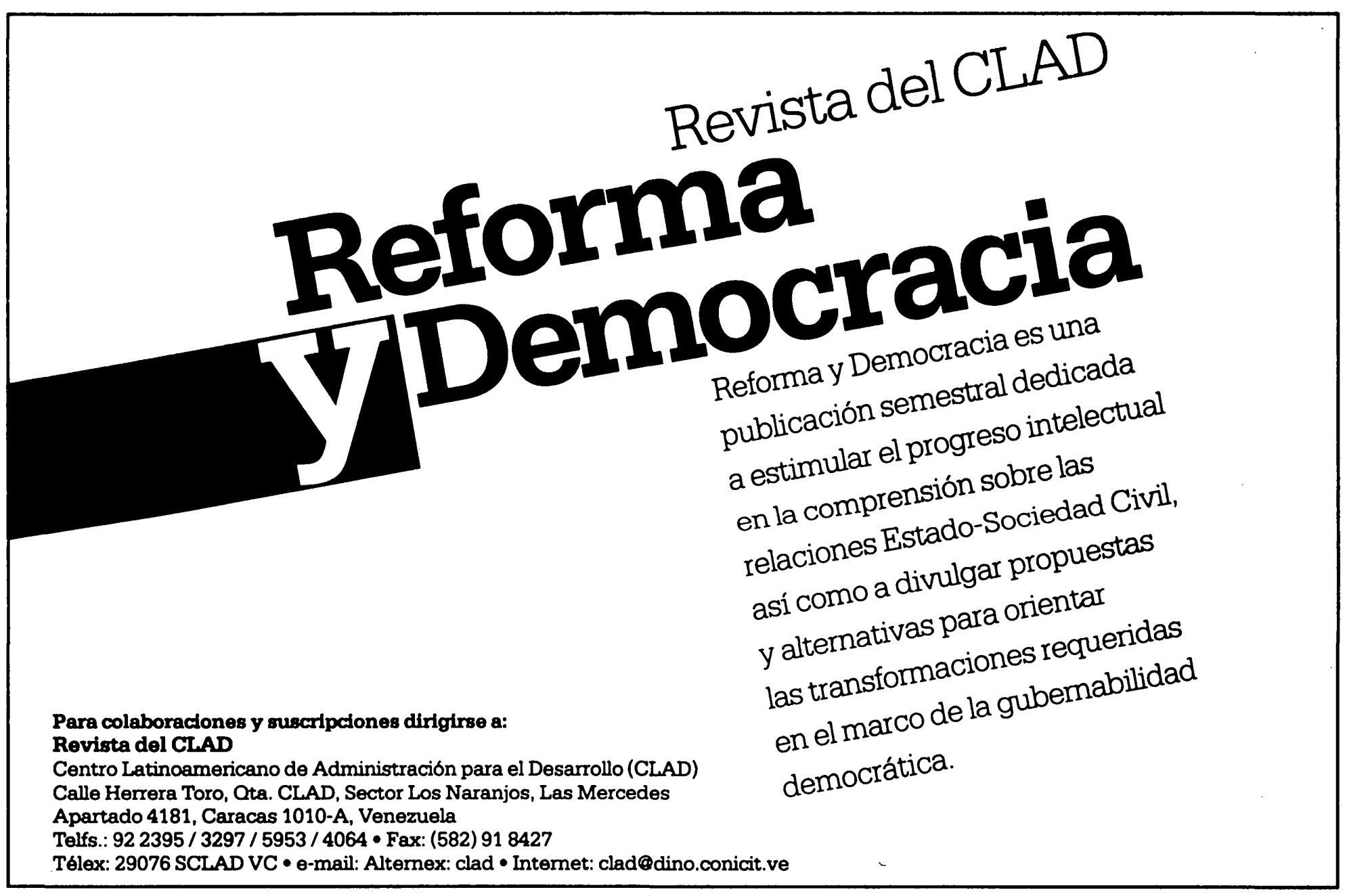

